The International Journal of Indian Psychology

ISSN 2348-5396 (e) | ISSN: 2349-3429 (p)

Volume 5, Issue 1, DIP: 18.01.068/20170501

DOI: $10.25215 / 0501.068$

http://www.ijip.in | October-December, 2017

Original Research Paper

\title{
Job Characteristics and Performance: The Mediating Role of Job Crafting
}

\author{
Dr. Chandrani Sen ${ }^{1 *}$, Ms. Surbhi Dulara ${ }^{2}$
}

\section{ABSTRACT}

The present paper aims to establish an exploratory research in the relationship between job characteristics and performance while evaluating the mediating role of job crafting. Service industry being the target zone with 100 middle level managers working in esteemed organizations (5 star hotels). Mediation analysis was assessed through PROCESS macro (Hayes, 2012) in SPSS. With correlational analysis it was explored that all the three variables were significantly and positively related. Job crafting as a mediator between the two constructs was also analyzed wherein it showcased a partial mediation between job characteristics and task performance and also between job characteristics and contextual performance. Therefore, it can be concluded that employees who engage in the acts of job crafting are more likely to perform better.

\section{Keywords: Job Characteristics, Job Crafting, Performance}

Service industry, in recent years, has emerged as a major employment sector in India with a rise in domestic as well as international tourism expanding the horizon of hospitality industry. A job is designed by identifying the various fragments and procedures required to meet the end results. Such tasks and procedures are determined via job characteristics:

"The specific aspects of job such as knowledge and skills, mental and physical demands, and working conditions that can be recognised, defined and assessed."

(Schuurman, 2011; Naude, 2010)

Job characteristics provide a blueprint of the job on the basis of the skills required to perform the job and the meaningfulness that job holds for the employees. And so, they serve as a motivating potential as they result in three psychological states: experienced meaningfulness, experienced responsibility and knowledge of results. Experienced meaningfulness is the product of skill variety, task identity and task significance, autonomy generates a sense of responsibility and feedback provides continuous knowledge of results. These psychological

\footnotetext{
${ }^{1}$ Sr. Asstt. Professor, The IIS University, Jaipur, Rajasthan, India

${ }^{2}$ Research Scholar, The IIS University, Jaipur, Rajasthan, India

*Responding Author

Received: April 28, 2017; Revision Received: November 15, 2017; Accepted: December 05, 2017

(C) 2017 Sen C, \& Dulara S; licensee IJIP. This is an Open Access Research distributed under the terms of the Creative Commons Attribution License (www.creativecommons.org/licenses/by/2.0), which permits unrestricted use, distribution, and reproduction in any Medium, provided the original work is properly cited.
} 
states determine how motivating the job is in itself. Depending on that motivation level the employee decides to reconfigure his/her job to make it more meaningful and more convenient to carry out the tasks and procedures by matching them to their own level of skills and expertise. This reconfiguration of job done by employee himself/herself is known as job crafting:

"The physical and cognitive changes individuals make in the task or relational boundaries of their work",

\section{(Wrzesniewski and Dutton in 2001).}

These physical and cognitive changes are made as per the individual's needs and as per the level of skills and abilities possessed by him to perform a specific task. The individual may change the order or number of tasks to be performed (task crafting), he/she may limit or expand his/her horizon of interactions with others depending on the need (relational crafting), or he/she may change the perception of the job to make it more meaningful and thus improving the motivation to perform that job (cognitive crafting). After reconfiguring the job on the basis of the three crafting behaviours, the employee performs the self-made job that matches his/her comfort level, skills and abilities. In organisational behaviour, performance is studied as a behaviour which is to be understood, predicted and improved upon. So in terms of behaviour, job performance is defined as:

"The value of the set of employee behaviours that contribute, either positively or negatively, to organisational goal accomplishment"

(Motowidlo, Borman \& Schmit, 1997; Campbell, 1990)

The behaviours that contribute positively are task performance and contextual performance, whereas the one which contribute negatively is counterproductive work behaviour. In this study, the focus is on positive contributors. Task performance refers to the "behaviours that directly or indirectly contribute to the organisation's technical core”, whereas contextual performance refers to the "behaviours that support the organisational, social and psychological environment in which the technical core must function"(Borman \& Motowidlo, 1993). Task behaviours are the one which vary from one job to another as per the job requirements and contextual behaviours are one which remains static across most jobs.

Although only a handful of studies have been conducted on job crafting as it's still in the pioneering stage in the field of empirical research, studies have shown a positive relationship exists between job characteristics and job crafting (Gu-Ne \& Young-Min, 2015; Kanten, 2014). There are limited studies which examine job characteristics with task and contextual performance individually. Although a positive and significant relationship has been found between job characteristics and task performance (Hernaus \& Mikulic, 2013; Onukwube \& Iyagba, 2011; Kahya, 2007) but studies examining a relationship between job characteristics and contextual performance are scanty. Again studies exploring the relationship between job crafting and performance are few. However, a positive and significant relationship has been seen between job crafting and task performance (Bakker, Tims \& Derks, 2012) and a 
significant indirect relation has been witnessed between job crafting and contextual performance through work engagement (Demerouti, Bakker \& Gevers, 2015).

\section{Objectives}

- To investigate the relationship between job characteristics, job crafting and performance (task and contextual performance).

- $\quad$ To examine the mediating role of job crafting between job characteristics and task performance as well as job characteristics and contextual performance.

\section{Hypotheses}

- $\quad$ There will be no significant relationship between job characteristics, job crafting and performance (task and contextual performance).

- $\quad$ There will be no significant mediating role of job crafting between job characteristics and performance (task and contextual performance).

\section{Research Design}

A correlational design was laid out in the light of above objectives and hypotheses.

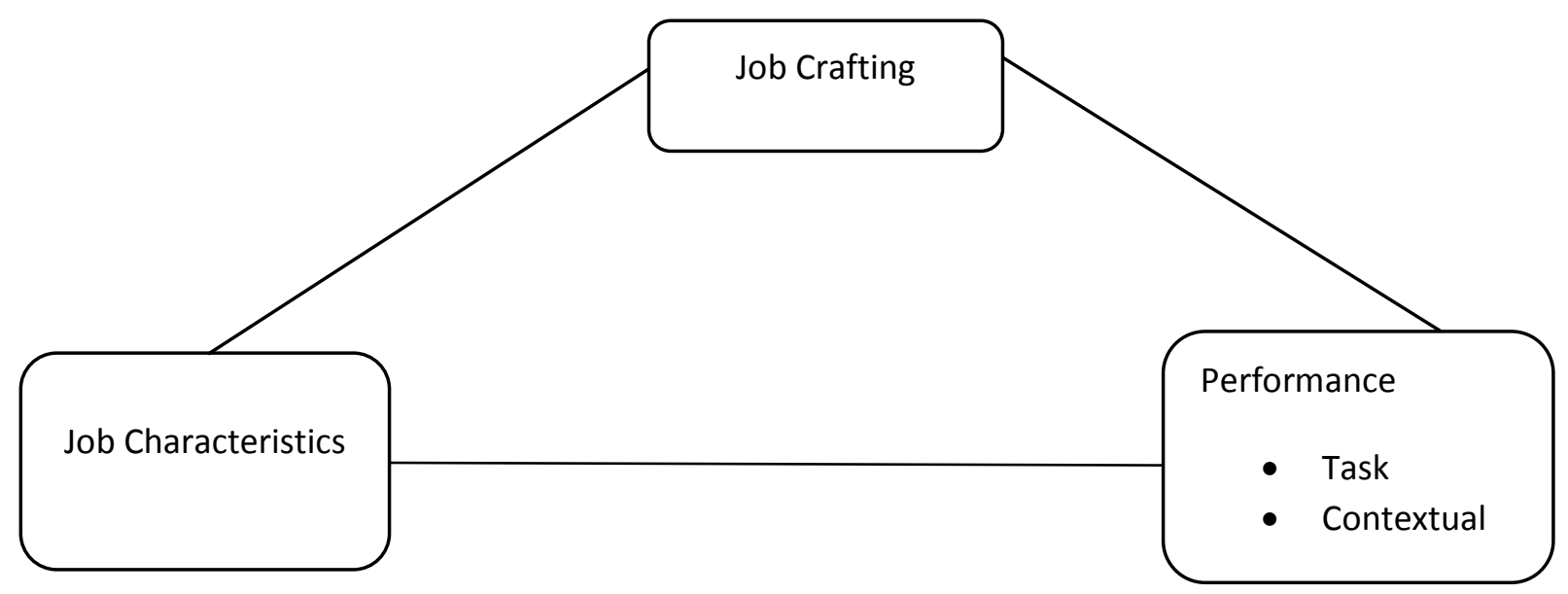

Mediational design was deployed after correlation.

\section{Sample}

The sample consisted of 100 middle-level managers working in 5 star hotels. The inclusion criteria being employees with a minimum tenure of 3 years with the current workplace and a minimum qualification of diploma in hotel management. As per the exclusion criteria gender was not taken into consideration and the employees on the probation period were not approached for data collection.

\section{Instruments}

- Job Diagnostic Survey (Hackman \& Oldham, 1980) was used to measure job characteristics. The scale consist of 15 questions. 3 questions are assigned to each core job characteristic, viz skill variety, task identity, task significance, autonomy and 
feedback. The instrument yields an overall score for job characteristics as well as independent scores for each core characteristic. (7 Point Likert Scale)

- Job Crafting Questionnaire (Slemp \& Vella-Brodrick, 2013) was used to measure the construct of job crafting which again consist of 15 questions. The questionnaire is divided into three dimensions representing the three job crafting behaviours: task crafting, relational crafting and cognitive crafting. This questionnaire also delivers score for each dimension as well as an overall score for job crafting behaviour. (6 Point Likert Scale)

- Individual Work Performance Questionnaire (Koopmans et al, 2014) was used to measure task performance and contextual performance. The questionnaire however, consists of three dimensions namely, task performance (5 items), contextual performance (8 items) and counterproductive work behaviour (5 items). This questionnaire only gives scores for each dimension of performance. (5 Point Likert Scale)

\section{Procedure}

The research was conducted in two phases:

Phase I: In the first phase data was collected from 100 middle level managers working in 5 star hotels on the basis of the inclusion and exclusion criteria. After data collection scoring was done as per the norms.

Phase II: After scoring, the data was analysed using SPSS. First descriptive statistics was computed followed by correlation. After obtaining significant correlation between all the three variables, mediation analysis was assessed using PROCESS macro(Hayes, 2012) in SPSS. The PROCESS is an amalgamation of regression and bootstrap method. The results are interpreted on the basis of beta coefficients and bootstrapping confidence interval to check for mediation.

\section{RESULTS AND DISCUSSION}

The present paper was conducted to explore the mediating role of job crafting between job characteristics and performance, i.e. task performance and contextual performance. As it is known, every job has a set of standard tasks and procedures. But the employees alter those set of tasks and procedures to meet desired levels of performance. So, the paper aims to explore the effect those alterations have on employee performance. 


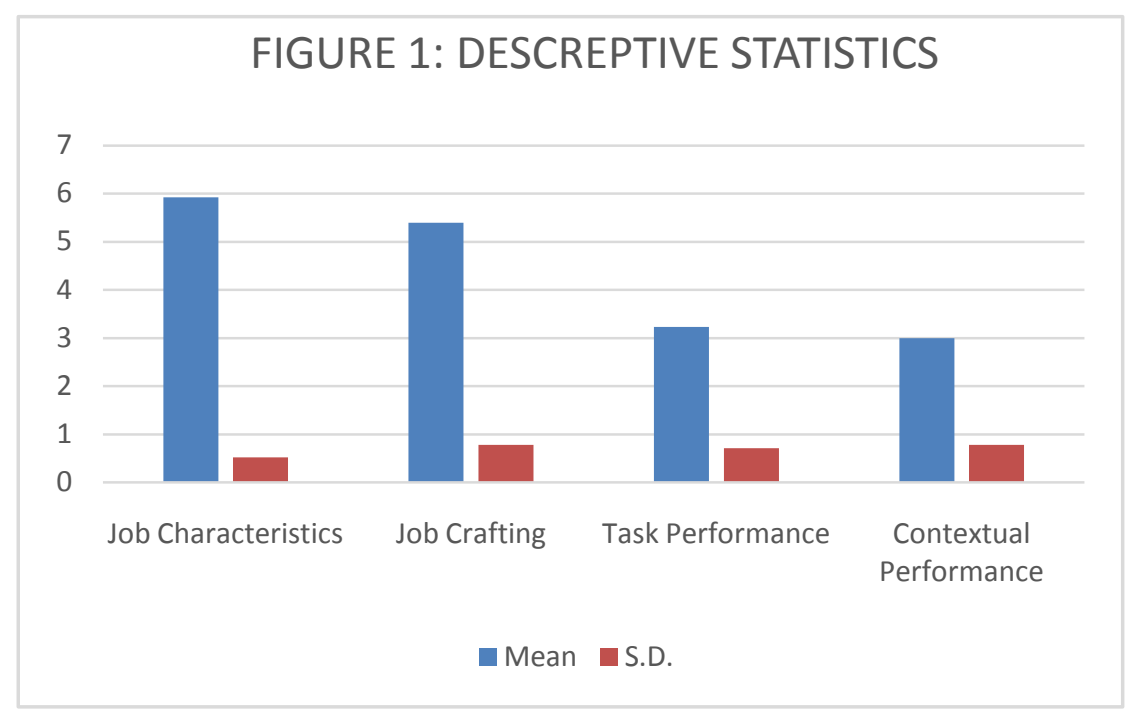

The first hypothesis was formulated to examine the relationship between job characteristics, job crafting and task and contextual performance.

Table 1.1, Correlation Matrix

\begin{tabular}{|l|l|l|l|l|}
\hline S. No. & \multicolumn{1}{|c|}{ Variable } & Job Crafting & Task Performance & \multicolumn{1}{c|}{$\begin{array}{c}\text { Contextual } \\
\text { Performance }\end{array}$} \\
\hline 1. & Job Characteristics & $.482^{* *}$ & $.573^{* *}$ & $.536^{* *}$ \\
\hline 2. & Job Crafting & --- & $.605^{* *}$ & $.587^{* *}$ \\
\hline \multicolumn{2}{|c|}{$\mathrm{N}=100$} \\
\hline
\end{tabular}

**Correlation is significant at the 0.01 level (2 tailed)

From the results of Table 1.1, it can be seen that a positive relationship exists between all the variables under the research. A positive and significant relationship exists between job characteristics and job crafting $(\mathrm{r}=.482, \mathrm{p}<0.01)$, job characteristics and task performance $(\mathrm{r}=$ $.573, \mathrm{p}<0.01)$, job characteristics and contextual performance $(r=.536, \mathrm{p}<0.01)$, job crafting and task performance $(\mathrm{r}=.605, \mathrm{p}<0.01)$, and job crafting and contextual performance $(\mathrm{r}=$ $.587, \mathrm{p}<0.01)$.

The results obtained are supported by studies conducted in past wherein a study conducted on sales consultants revealed a positive relationship between job characteristics and job crafting (Gu-Ne \& Young-Min, 2015). Another study conducted on hotel employees revealed job characteristics as a significant predictor of job crafting (Kanten, 2014). Job characteristics is seen to influence task performance more than contextual performance (Hernaus \& Mikulic, 2013). Moreover, several studies have shown a positive relationship between job characteristics and task performance (Onukwube \& Iyagba, 2011; Kahya, 2007).A significant indirect relationship between job crafting and contextual performance through work engagement has been seen (Demerouti, Bakker \& Gevers, 2015). Also, job crafting through work engagement is found to have a significantly indirect relationship with task performance 
(Bakker, Tims \& Derks, 2012).Hence, present paper is in congruence with the previous findings.

After correlation analysis, mediation analysis was performed using PROCESS macro in SPSS. First, job crafting was investigated as a mediator between job characteristics and task performance (hypothesis 2).

\section{Figure 2.1}

The regression-based path coefficients of the mediation analysis of job crafting in the relationship between job characteristics and task performance.

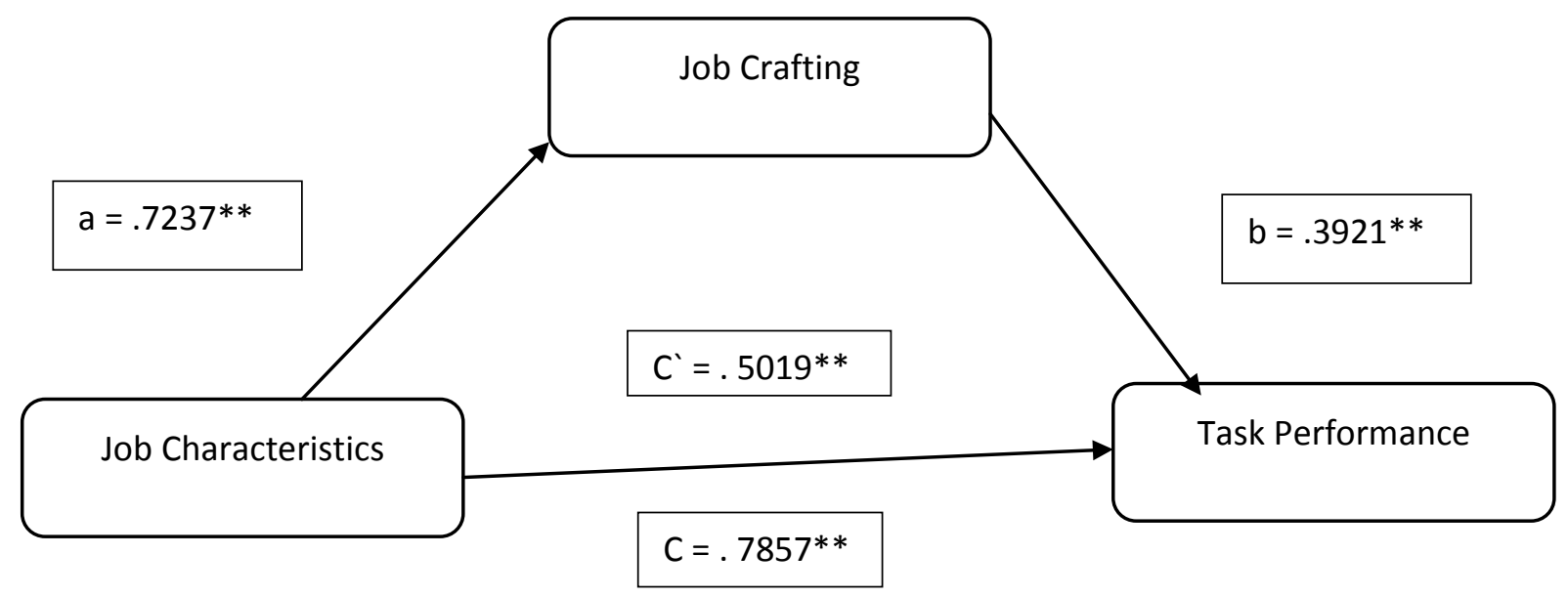

The results of mediation analysis as per regression-based approach can be seen in Figure 2.1. The total effect of job characteristics on task performance came out to be significant ( $c=$ .7857, $\mathrm{SE}=.1136, \mathrm{t}=6.9141, \mathrm{p}<0.01$ ). After entering job crafting into the equation, the indirect effect of job characteristics on task performance again came out to be significant (c`= $.5019, \mathrm{SE}=.1158, \mathrm{t}=4.3325, \mathrm{p}<0.01)$. The direct effect of job characteristics on job crafting $(\mathrm{a}=.7237, \mathrm{SE}=.1329, \mathrm{t}=5.4461, \mathrm{p}<0.01)$ and job crafting on task performance $(\mathrm{b}=.3921$, $\mathrm{SE}=.0772, \mathrm{t}=5.0815, \mathrm{p}<0.01)$ was found to be significant. From the results of regressionbased approach it can be seen that job crafting partially mediate the relationship between job characteristics and task performance as both the direct (c) and indirect (c') relationship of job characteristics on task performance came out to be significant.

Next, job crafting was examined as a mediator between job characteristics and contextual performance (hypothesis 3).

\section{Figure 2.2}

The regression-based path coefficients of the mediation analysis of job crafting in between the relationship of job characteristics and contextual performance. 


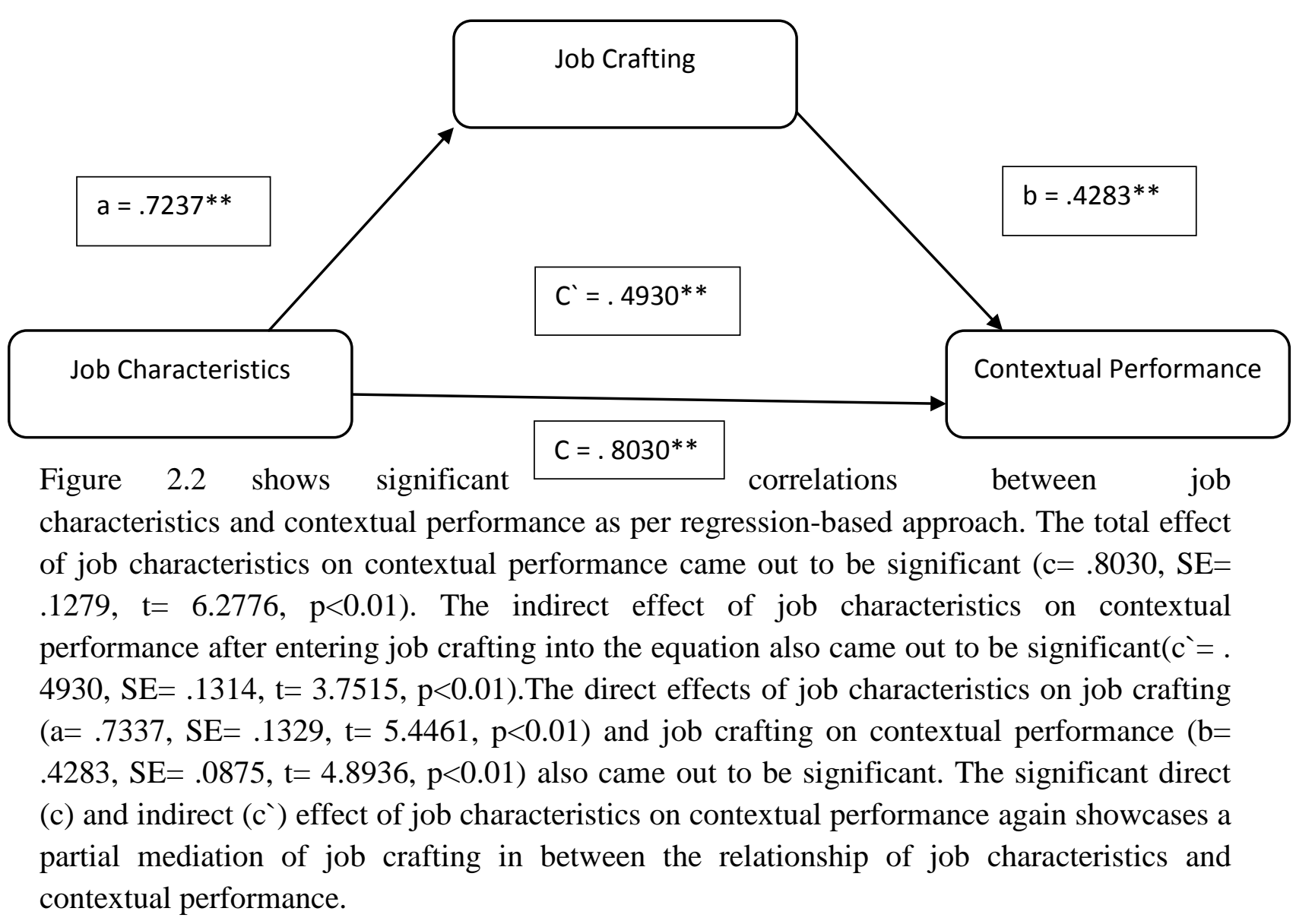

Finally, the indirect effect of job characteristics on task performance as well as contextual performance through job crafting is shown in Table 1.2 below.

Table 1.2, Parameter estimates of 1000 bootstrap samples with bias corrected and accelerated bootstrap confidence intervals (BCa CI) at 95\% confidence level.

\begin{tabular}{|l|l|l|l|l|}
\hline & \multicolumn{2}{|c|}{ Product of coefficients } & \multicolumn{1}{c|}{ Bootstrapping 95\% BCa CI } \\
\hline \multicolumn{1}{|c|}{ Effects } & $\begin{array}{c}\text { Parameter } \\
\text { Estimate }\end{array}$ & SE & Lower CI & Upper CI \\
\hline JC $\rightarrow$ Crafting $\rightarrow$ TP & .8238 & .01093 & .1593 & .5967 \\
\hline JC $\rightarrow$ Crafting $\rightarrow$ CP & .3100 & .1058 & .1680 & .5809 \\
\hline \multicolumn{5}{|c|}{$\mathrm{N}=100$} \\
\hline
\end{tabular}

Table 1.2 represents the bias corrected and accelerated bootstrap confidence intervals (BCa CI) results as per the PROCESS macro in SPSS. The indirect effect of job characteristics on task performance through job crafting $(\mathrm{PE}=.2838$, 95\% BCaCI[.1593,.5967]) and the indirect effect of job characteristics on contextual performance through job crafting ( $\mathrm{PE}=.3100,95 \%$ BCa CI [.1680, .5809]) came out to be statistically significant as it does not include zero in the 95\% bias corrected and accelerated confidence interval (BCa CI) and so the indirect effects are statistically different from zero. From the results of indirect effects, it can be inferred that although job characteristics provide a baseline of expected performance, it is through customizations in those set standards that employees are able to perform better and

(C) The International Journal of Indian Psychology, ISSN 2348-5396 (e)| ISSN: 2349-3429 (p) | 72 
give desired output. These customizations are a result of job crafting behaviours that employees undertake to operate as per their convenience to give effective results. There were no studies found to support the results of the mediation analysis as job crafting is a pioneering variable. Hence, the findings of this paper provides novel viewpoints which will contribute to the existing literature and provide direction for further empirical developments.

\section{CONCLUSION}

For long, individuals have been engaging in the practice of modifying their task schedules as per their own preference. However, it is only in the recent years that this practice has been recognised and is labelled as job crafting. Although, this new construct is still in its infancy stage in empirical investigations but it has emerged as an essential ingredient towards improved efficiency and effectiveness of performance resulting in various positive outcomes like well-being, engagement, commitment and low turnover to name some. So, it can be concluded that job crafting provides a pathway towards better performance by giving the employees' the liberty to modify their task procedures and interrelationships at work and hence, job crafting behaviours serve as a pathway between set standards of tasks and procedures and target output to result in better and improved performance.

\section{Acknowledgments}

The author appreciates all those who participated in the study and helped to facilitate the research process.

Conflict of Interests: The author declared no conflict of interests.

\section{REFERENCES}

Bakker, A. B., Tims, M., \& Derks, D. (2012). Proactive personality and job performance: the role of job crafting and work engagement. Human Relations, 65(10), 1359-1378.

Borman, W. C., \& Motowidlo, S. J. (1993). Expanding the criterion domain to include elements of contextual performance. In N. Schmitt, and W. C. Borman (Eds.), Personnel selection in organizations (pp. 71-98). San Francisco: Jossey Bass.

Campbell, J. P. (1990). Modeling the performance prediction problem in industrial and organizational psychology. Handbook of industrial and organizational psychology, 1(2), 687-732. Palo Alto, CA: Consulting Psychologists Press.

Demerouti, E., Bakker, A. B., \& Gevers, J. M. P. (2015). Job crafting and extra-role behaviour: The role of work engagement and flourishing. Journal of Vocational Behavior, 91, 87-96.

Gu-Ne, Kim and Young-Min, L. (2015). Towards High Performance Organization: The Impacts of Job Characteristics and Job Crafting. Advanced Science and Technology Letters, 114, 26-32.

Hackman, J.R., \& Oldham, G.R. (1980). Work redesign. Reading, MA: Addison-Wesley.

Hayes, A. F. (2012). PROCESS: A versatile computational tool for observed variable mediation, moderation, and conditional process modeling. Retrieved from http://www.afhayes.com/ public/process2012.pdf 
Hernaus, T., \& Mikulic, J. (2013). Work Characteristics and Work Performance of Knowledge Workers . EuroMed Journal of Business 9(3), 1-28.

Kahya, E. (2007). The effects of job characteristics and working conditions on job performance. International Journal of Industrial Ergonomics, 37(6), 515-523.

Kanten, P. (2014). The antecedents of job crafting: Perceived organizational support, job characteristics and self-efficacy. European Journal of Business and Social Sciences, 3(5), 113-128.

Koopmans, L., Bernaards, C.M., Hildebrandt, V.H., Buuren, S. V., Beek, Allard, J., Vet, H.C.D. (2014). Improving the Individual Work Performance Questionnaire using Rasch analysis. Journal of Applied Measurement, 15(2), 160-175.

Motowidlo, S. J., Borman, W. C., \& Schmit, M. J. (1997). A theory of individual differences in task and contextual performance. Human Performance, 10, 71-83.

Naude, O.F. (2010). Skilled Staff's Job Characteristics, Job Satisfaction and Intentions To Quit in a Petrochemical Company.(Unpublished Master's thesis). North-West University Potchefstroom Campus.

Onukwube, H.N., \& Iyagba, R. (2011). Construction Professionals Job Performance and Characteristics: A Comparison of Indigenous and Expatriate Construction Companies in Nigeria. Australasian Journal of Construction Economics and Building, 11(2), 71.

Schuurman, J. (2011). Job Characteristics, Health and Satisfaction, Can Satisfaction with Social Life Overcome Negative Job Traits?.(Unpublished Master's Thesis). Erasmus University, Rotterdam.

Slemp, G. R., \&Vella-Brodrick, D. A., (2013). The job crafting questionnaire: A new scale to measure the extent to employees engage in job crafting. International Journal of Well-being, 3(2), 126-146.

Wrzesniewski, A., \& Dutton, J. E. (2001). Crafting a job: Revisioning employees as active crafters of their work. Academy of Management Review, 26, 179-201.

How to cite this article: Sen C, \& Dulara S (2017). Job Characteristics and Performance: The Mediating Role of Job Crafting. International Journal of Indian Psychology, Vol. 5, (1), DIP: 18.01.068/20170501, DOI: 10.25215/0501.068 